\title{
IMPOSTO SOBRE O VALOR AGREGADO (IVA) E HARMONIZAÇĂO TRIBUTÁRIA E FISCAL NO MERCOSUL
}

Jhana Kiyosen Nakayama*

SUMARIO: 1. Introducăo; 2. Origem e Conceito; 3. WA no Mercosul; 4. Condusäo; 5. Biblografia

SUMMARY: 1. Introduction; 2. Origin and concept; 3. IVA in the Mercosul; 4. Conclusion; 5. Bibliography.

ÜBERSICHT: 1. Einführung; 2. Herkunt und honzept; 3. Tva in der Mercosul; 4. Schlussfolgerungen; 5. Bibliographie.

RESUMO: O presente estudo analisa o IVA no Mercosut destacando as vantagens e desvantagens do mesmo.

ABSTRACT: The present sudy analyses the IVA in the Mercosul detaching the advantages and disadvantages of the same.

ZUSAMMENFASSUNG: Die vorliegende Arbeit untersuch der IVA in der Mercosul und hebt dabei ihren Vortele und Nachteile.

BALAVRAS-CHAVE: NA no Mercosul. Coondenaçao legislativa. Harmonizacăo legisiativa.

KEY-WORDS: IVA in the Mercosul. Legislative coordination. Legisltive harmonization.

SCHLUSSELWORTER: IVA in der Mercosul.

Legislativkoordinierung. Legislativharmoniesierung. 


\section{Introdução}

A intenção deste ensaio é introduzir o tema imposto sobre o valor Agregado com reflexöes acerca da coordenaça e posterior hamonizaçäo tributaria e fiscal no Mercosul e no Brasil.

Em 26 de marco de 1991, originou-se o Mercado Comum do sul (Mercosul), através do Tratado de Assunção, tendo como membros, Argentina, Brasil, Paraguai e o Uruguai, O Tratado de Assunção declara a intencăo de constituir un mercado comum. Nesta futura etapa do mercado comum, considerado um estágio mais aprofundado que compreende a livre circulação de todos os fatores de produça com a eliminaça de barreiras e o estabelecimento de uma tarifa externa comum para paises signatários do Tratado de Assunçâ, implica na aplicaçăo das cinco liberdades que são a livre circulaça de mercadorias, a liberdade de estabelecimento, a livre circulação de trabalhadores, livre circulação de capitais e liberdade de concortência.

O Tratado de Assunção tem como princípios orientadores, para o alcance de seus objetivos: a lexibilidade, a gradualidade, o equilibrio e a reciprocidade. A llexibilidade funciona como diretiva de procedimento para a tomada de deliberaçóes para a execução do Tratado e flexibilidade na interpretacão. O equilíbrio visa determinar que a integracão näo ocona com o sacrificio de em Estado, em proveito dos demais, sem um devido programa de compensação para a região. A reciprocidade trata-se de um sistema mútuo de controle da execuça e aplicação do Tratado, onde cada Estado-parte assume direitos e obrigaçöes eqüitativas. A gradualidade demonstra a intença dos Estados-partes de que a integracăo ocoma em etapas definidas para adequaçóes necessárias para a adaptação para a abertura parcial e seletiva dos mercados.

Elba Cristina Lima Régo avalia o desempenho no Mercosul dizendo que este bloco comecou a funcionar como zona de livre comercio e uma união aduaneira parcial em 12 de janeiro de 1995 , com o fim do período de transição fixado no Tratado de Assunçăo. A uniăo aduaneira não é plena porque há políticas comerciais diferenctadas no unverso tarifário, com produtos na lista de excecões. Em 1994, estas listas näo deveriam ultrapassar 
299 posiçóes tarifárias da Nomenclatura Comum do Mercosul para o Brasil, Uruguai e Argentina. A lista do Paraguai, tambëm, näo deveria ultrapassar os 399 itens tarifários para a Nomenclatura Comum do Mercosul'.

Tribunal de Justiça das Comunidades Européias define mercado comum como uma fusão de mercadorias nacionais após a fusão, esse merado que é um só, passa a atuar como se fosse um mercado interno. Werter R. Faria diz que a união aduaneira, iniciada com o Protocolo de Ouro Preto, conseguiu-se $80 \%$ dos produtos com inclusão na tarifa externa comum, produtos estes objeto do comércio pelo quatro paises ${ }^{2}$.

Pelo dicionário Webster, mercado comum significa uma receita econômica formada para remover barreiras comerciais entre estados membros. No plano econômico, por Joāo Melo Franco e Herlander Antunes Martins, mercado comum significa alargamento do mercado para os empreendimentos que estejam localizados em qualquer um dos paises que decida suprimir os encraves aduaneiros ao comércio ${ }^{3}$.

Apesar deste bloco não estar, ainda, na lase de mercado comum, para que a etapa se concretize, é necessârio a supressão de barreiras fiscais e tributárias e, para isso, a harmonização das normas tributárias, inclusive do Imposto sobre o Valor Agregado (IVA) no Mercosul. A adoção deste imposto no Brasil ou de algum outro tributo sobre consumo e sobre serviços é primordial. E, para a futura concretização do IVA no ámbito do Mercosul, é essencial que o princípio da gradualidade seja efetivamente seguido; passando-se etapa por etapa para se alcançar a integração no bloco.

\section{Origem e conceito}

No Egito antigo, há 3300 anos a.C., qualquer mercadoria em tränsito do lugar de produção ao local de consumo estava sujeita a uma imposição fiscal. Os gregos e os romanos estipularam forma de tributação sobre os

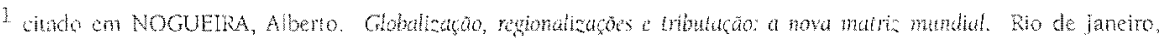
Renoyar, 2000 . $16+165$

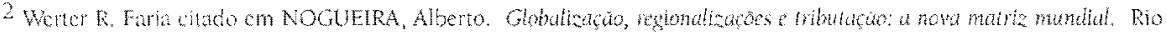
Ue Junero, Echow, 2000 . p. $174+176$

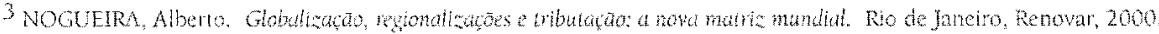
p. 178
} 
negócios realizados, sendo que os impostos incidentes sobre as transferencias e vendas de mercadoria serviam como recurso financeiro destinado à protecão do comércio. A centesima rerum venalium, de $9 \mathrm{~d}$. C., instituida pelo Imperador romano Augusto tinha a finalidade de custear gastos militares, que incidia sobre o giro dos negocios com uma alfquota de $1 \%$ sobre as mercadonias vendidas em leiläo público. Em 1292, o rei Felipe da França impôs alíquota de 5 a $12 \%$ sobre todas as vendas e compras, exceto as correspondentes a alimentos, respeitando as pequenas quantidades.

Pode-se dizer que a origem do imposto sobre o valor agregado deu-se com os estudos de Nicholas Kaldor", em 1950, que elaborou um modelo tributário para um imposto abrangente sobre o consumo. Reunia, em um só tributo, neutralidade econômica, justiça fiscal e relação direta entre o contribuinte e o Fisco. O contribuinte declararia seu consumo com incidencia do tributo em razão do montante e da composiçào do gasto de cada um. Haveria, ainda, previsão de aliquotas progressivas. Em 1952, a Franç introduz o imposto sobre o valor agregado, a TVA (Taxe Sur La Valeur Ajoutée), substituindo o imposto sobre a producăo.

A rica experiencia francesa se difundu velozmente a partir da decada de 60 . O Brasil introduziu na Constituicäo principio da näo cumulatividade com a Reforma Constitucional n.18, de 1965, embora ja o tivesse adotado, em legislaça ordinária, no Imposto de Consumo; a Comunidade Economica Européia adota o mposto sobre o valor adicional como projeto de sua primeira diretriz finalmente aprovada pelo conselho em 1967, sendo paulatinamente implementada por seus membros; alemanha o introduz a partir de 1968; a Dinamarca, pela lei de marco de de 1967; 0 Luxemburgo e a Bélgica, em 1969. A partir do final dos anos 60, também esse lipo de tributo sobre vendas liquidas se difunde por toda a América Latina (Bolivia, Unuguai, Peru, Equador, Argentina), sendo recentemente

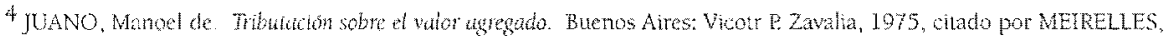

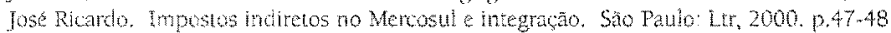

5 citado por REZLWDE. Forando. A moderna tributaça do consmo. In: MATTOS FLLHO Ary Oswallo. (coord.)

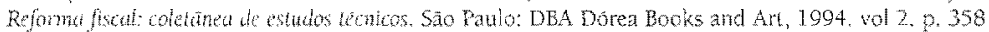


introduzido no Paraguai, em 1972, para futura harmonizaçăo no Mercosult.

Em 1958, o Brasil adota um modelo de tributo não cumulativo, o imposto de consumo, Surge, então, uma tendência de se colocar todo o setor produtivo dentro de um único estabelecimento, a verticalizaçăo. Houve, assim, influência da tributação para economizar tributo. No Brasil não há tributação sobre o valor agregado porque o sistema é de imposto contra imposto, pois as aliquotas são diferentes e o sistema de crédito não tributa o valor agregado de forma exata.

Os paises que se utilizam do valor agregado, ou seja, de base contra base e não de imposto contra imposto, a base tributada e näo imposto recorrente, trabalham com o método da adição ou método de subtração, ambos com o mesmo resultado, tributando sempre essa diferença, que se chama valor agregado?

Maria A. Allegreti de Salgado definiu o imposto sobre o valor agregado, como aquele que recai sobre o consumidor final, que é quem definitivamente paga o imposto através do consumo, com ingresso no Fisco por cada uma das etapas do processo econômico de produção, distribuição e comercialização, proporcional ao valor que cada uma das etapas incorpora ao produto. É um imposto geral e uniforme com diferenciaçóes nos sistemas tributários dos paises que o adotam.

IVA, Imposto sobre o valor agregado ou acrescido é um imposto indireto, para a tributação do consumo em geral, incidente sobre a cadeia produtiva e de distribuição de mercadorias para o consumidor final. A tributaçāo sobre os serviços, pode ou não ser incluída no âmbito do Mercosul, o que ficará na pendencia de futura harmonização tributária. Imposto fundamental para a efetiva integração entre os Estados partes do Mercosul.

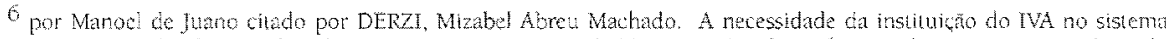

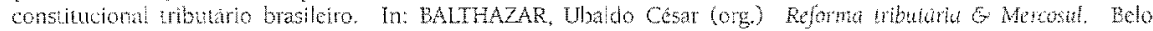
Horizonte: Del Rey 1999. p.19.

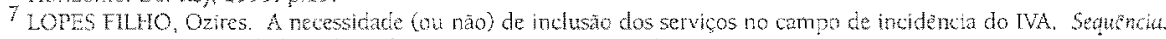
torunopolis: Universidade Federal de Sama Carana, 1995 , vol 16, p.31-33.

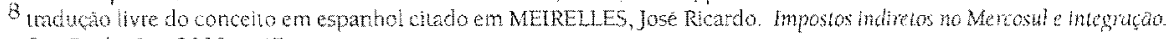
Sto Paulo: Lit, 2000 p.47.
} 
O lato gerador do IVA consiste nas entregas de bens e prestaçäo de serviços e nas importaçoes de produtos e mercadorias. A base imponivel consiste na totalidade da contraprestaçăo de cada operação sujeita ao imposto. O objeto do IVA, a seu tumo, É consumo, jâ que através da repercussão economica, transfere-se a carga tributaria do contribuinte de direito para o contribuinte de fato, consumidor final".

O Principio da onigem ocorre quando o fornecedor cobra o IVA quando enviar a mercadoria para o consumidor localizado em outro Estadoparte. O fornecedor utiliza a sua aliquota interna de seu país e o Princípio do destino caracteriza-se quando do fornecimento da mercadoria entre os Estados-partes, impondo alíquota zero nas exportações e da alíquota do domicílio do consumidor ou importador. Quanto ao IVA no Mercosul, todos os países do Mercosul adotam o princípio da tributação exclusiva no destino. Assim, há o benefício para o país onde se da o efetivo consumo do bem. Caso haja opção pelo principio do destino, dispensa-se harmonização legislativa, garante-se um certo nivel de integração e a manutenção da base de incidencia e aliquotas próprias de cada Estado-parte, porém neste principio, inexiste a possibilidade de eliminaçăo de aduanas entre os Estados-partes.

Por que o legislador brasileiro propôs a tributaçảo sobre mercadoria no ICMS e servico no $155 \mathrm{em}$ nivel municipal? ... o regime federativo pode provir nalualmente de duas origens diversas, seja advindo de um tratado concertado entre antigos Estados soberanos e independente, a exemplo do caso classico dos EUA, seja ainda de um movimento histónico de cunho nacional, como no Brasil em 1889, que de regine monarquico e unitário passou a uma república federativa"

O início da colonização brasileira constituiu um presságio da diliculdade de adaptação do pacto federal no Brasil, face à dispersäo de interesses na sua estrutura organizacional ${ }^{12}$. Desde logo é preciso esclarecer que no Estado federal, exatamente porque existe partilha interna de competências, o que ocorre é que o poder constituinte da federação, reservada a competencia

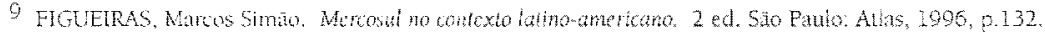

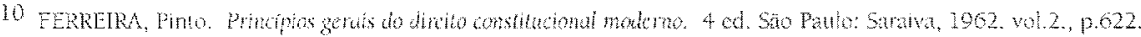


constitucional especifica de "constituir" a unidade federada". Vê-se, pontanto que o caso do Brasil, como Estado Federal, decorreu de um movimento histónico $e$, por isso, refletir-se-á nas competências remanescentes do Estado-membro.

Estado federal introduziu modificações profundas nas relações juridicas entre os seus componentes, com o surgimento de uma nova entidade, que é o Estado-membro, considerado por alguns como forma de organizaçăo política. Bernard Schwartz entende o termo Federalismo como aquele usado para descrever qualquer organizaçăo em que estados independentes concordam em delegar poderes a um governo comum com vista a Constituiçōes inteiramente novas, mesmo dos próprios estados ${ }^{13}$.

Brasil é uma federação e isso exige que se atribua um imposto onde a arrecadação dos entes que compoem a federação supra as suas necessidades.

\section{IVA no Mercosul}

O art. 1o. do Tratado de Assunção estabelece que a constituição do Mercosul implica em livre circulaçăo de bens, serviços e fatores produtivos entre os Estados-partes com eliminação de direitos aduaneiros e restriçóes não aduaneiras à circulaçao de mercadorias e de qualquer medida equivalente. Um dos aspectos mais relevantes do processo de integração entre os paises do Mercosul, diz respeito à eliminação de diferenças legislativas que possam dificultar ou obstaculizar o seu desenvolvimento.

0 art $7^{\circ}$ do Tratado de Assunção aborda especificamente a questão tributária com previsäo de impostos, taxas e outros gravames intemos para os produtos originários do territórios de um Estado-parte tratamento idêntico ao fornecido ao produto nacional. O Tratado de Assunção estabelece

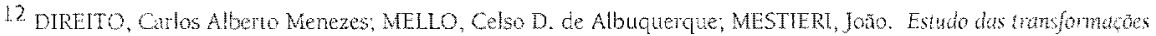

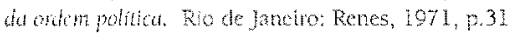

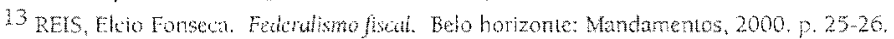


como critério da tributação por parte dos impostos internos o princípio da näo discriminaçāo ${ }^{14}$.

No âmbito tributärio significa a busca de coordenação que facilite o desenvolvimento comercial, excluindo a guerra fiscal, ou beneficios em favor desta ou daquela empresa ${ }^{5}$. Visa promover a harmonização dos países do bloco do Mercosul, para que possa ser alcançada a justiça necessáría e a segurança nas relaçōes comerciais e sociais intemacionais. A coordenação é entendida como o estabelecimentos de estratégias comuns entre os Estados que integram blocos ou mercados. As legislaçóes são pouco aproximadas, onde os Estados ser propóem a adotar políticas deliberadas ${ }^{16}$.

Há necessidade de harmonização dos impostos indiretos sobre o consumo, caso do IVA, cujo ônus econômica é transferido para o consumidor final por meio de mecanismos dos preços, visa a impedir distorçoes na livre concorrencia entre produtos e serviços provenientes de todos os paises integrados. Consiste, fundamentalmente, na decisão sobre qual o pafs, o da origem ou o do destino, das operaçoes intra-regionais de circulaça de mercadorias e serviços detera a potestade exclusiva de tributar o seu consumo, bem como no compromisso reciproco de näo-discriminaçăo, que garante aos bens importados de outros paises membro tratamento identico ao dispensado aos similares nacionais ${ }^{17}$.

Para melhor compreensão do cenário do Mercosul sobre os impostos sobre o consumo, serão expostos quais impostos de maior destaque nos paises integrantes do bloco, vejamos:

- Argentina: imposto sobre o valor adicionado e impostos internos, de competência federal, e impostos sobre o ingresso bruto, de competência provincial, imposiçôes sobre combustiveis liquidos, a nivel lederal e sobre energia elétrica, a nivel provincial e municipal.

14 LANGEMANN. Eugetrio. Hả recessidade de um imposto único sobre onsumo no ambilo do Mercosul. Sequência. Flotianopols: Universidade Federal de 5antat Catarina, 1995, vol 16, 1.54 .55 .

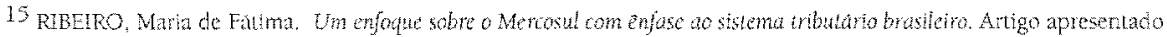

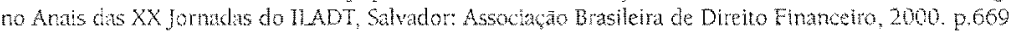

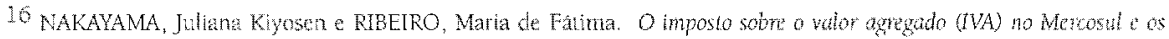

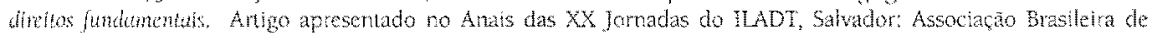
Direito Financeiro, 2000. p. $685+713$.

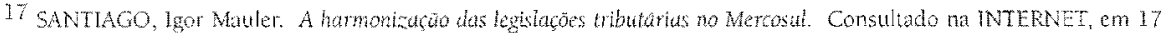
de janeiro de 200 , hlp:/wwwedlo.combr. 
O IVA na Argentina é um dos pilares básicos do sistema tributário, por ser um dos impostos com maior arrecadação dos últimos anos e admite maior elasticidade em função das necessidades arrecadação e da política tributária $^{1 R}$. E o principal imposto incidente sobre o consumo na Argentina em fase da sua abrangência e características próprias. A năo cumulatividade é insita à essência do IVA, sob pena de tomar-se modalidade de tributo onerosa, o que inviabilizaria economicamente sua aplicação ${ }^{19}$. Na Argentina, - IVA é de competencia nacional (Lei 23.349/85, regulamentado pelo Decreto 2.407/86; Lel 20631, de 29/12/1973, em vigor a partir de 01/01/1975; Lei 25239, de 31.12.99, Decretos Regulamentadores 2407, 2510 e 1920 e Revolução 680/99), havendo um sistema de distribuição para as Provincias e Códigos Tributários Provinciais. O seu funcionamento tem características do ICMS brasileiro. As operaçôes tributadas são a venda ou importaça de produtos e prestaça de serviços com alíquotas que chega ao máximo de $27 \%$, numa média de $21 \%$.

- Brasil: impostos sobre produtos industrializados, competencia federal; imposto sobre circulação de mercadorias e serviço de transponte e comunicação, de competência estadual; imposto sobre serviço, competência municipal.

No Brasil não há incidência do IVA. Há necessidade de alterar as competências tributarias dos Estados, da União e dos Municipios, quer seja, do IPI (Imposto sobre Produtos Industrializados), ICMS (Imposto sobre Operaçōes Relativas à Circulação de Mercadorias e Prestação de Serviços de Transporte e de Comunicaçōes) e ISS (Imposto sobre Serviços de quaisquer natureza)

- Paraguai: imposto sobre o valor adicionado, impostos seletivos, imposto único, imposto sobre a comercialização de gado vacum, de competência nacional e serviços diversos, de competência municipal.

\footnotetext{
13 waduch twe de URRESTh, Esteban Juan e CARDOZO, Horacio Fellx. Comentarios sobre la instauracion del

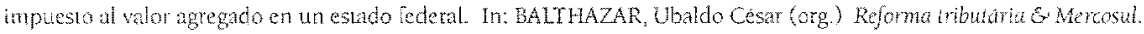
Lelo Horizonte: Del Rey, 3999, p. 163.

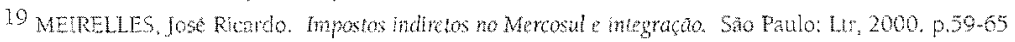


O Paraguai moldou-se aos padrões internacionais e à competitividade externa com adequaçăo à tributaça interna, principalmente no que se refere ao IVA, desde a promulgaçăo da Constituição em 1992. O Paraguai ainda manteve política de incentivo à produção agrícola e agropecuária, desonerando os atos a elas diretamente relacionadas $\mathrm{A}$ base de cálculo corresponde ao líquido do preço ou do serviço, deduzindo do valor correspondente a bonificações ou descontos vigentes no mercado interno que conste na fatura em outros documentos. Vigora a aliquota de 10\%. Para as importaçōes, houve redução da base de cálculo em $20 \%$ por conta do regime especial, com incremento nas importaçoes. É cobrado pela Uniāo, imposto de âmbito nacional ${ }^{20}$. No Paraguai, a Lei 125 , sancionada em 28.12.91 e promulgada em 9.1.92, no Título Primeiro do Livro III (imposto sobre o consumo) nos arts. 77 a 98 da, regulamentada pelo Decreto 13.424/92, instituiu o IVA, onerando todas as transações comerciais, inclusive serviç, tendo por base o valor da operaçăo, e com aliquota básica de $8 \%$.

- Unuguai: imposto sobre o valor adicionado, imposto especifico interno, adicionais ao imposto sobre vendas de bens agropecuários, imposto para o fundo de inspeção sanitária, imposto sobre compra e venda de bens em hasta publica, imposto sobre vendas forçadas, de competência nacional; imposto sobre venda de semoventes e sobre remates de bens móveis, imóveis e semoventes de competência departamental.

No Uruguai, a Lei 14.100, de 29 de dezembro de 1972 implantou o NA, com regulamento no Código Tributário Uruguaio de 1996, Titulo 10, art. 1 a 86 , que tributa serviços, mercadorias e serviços em geral com alíquota básica de $23 \%$.

Os quatro paises integrantes do Mercosul, como ja referido, adotam em seus sistemas tributarios impostos incidentes sobre o consumo, segundo a técrica do valor agregado. Argentina, Uruguai e Paraguai promovem a sua incidencia por seus govemos centrais. O Brasil, como sabido, possui um amplo imposto seletivo,

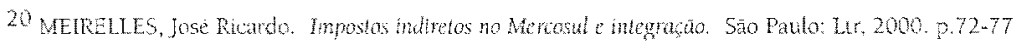


o IPI, na competencia Jederal; o mais amplo imposto sobre o consumo, o ICMS, está na competencia estadual

Conclui-se desta afirmativa, que cada Estado-Membro tem sua legislação especílica quanto aos sistemas tributários e as suas aliquotas, o que traz problemas para a harmonização tributária no Mercosul.

Hugo González Cano diz que a harmonizaçao tributária consiste no processo de ajuste das estruturas tributarias dos paises-menbros, com a finalidade de compatibilizá-las com os objetivos de um determinado tipo de integraçäo. (...) ${ }^{2 z}$ Estes mecanismos podem se constituir na compatibilização da legislaça e na uniformização, que implicaria igualar as legislaçoes em todos os aspectos. Diz ainda que os processos de integração econômica requerem certo grau de hamonizaçăo tributária, cuja intensidade se vincula com o tipo de integração e a etapa do processo vigente em cada caso ${ }^{23}$.

Claudino Pita ${ }^{2-4}$ acrescenta que a harmonização tributaria es um processo através do qual vários paises eletuam modificaçes em comum acordo nos seus sistemas tributários para compatibilizá-los. Nāo gerando, dessa forma, distorçes que possam afetar suas relaçöes econômicas no contexto de um tratado de integração econômica. A hamonizaça é a adequaçăo, e não a unificaço, de critérios comuns para eliminar ou reduzir distorçoes resultantes das divergências de maior gravidade.

0 processo de integração depende da coordenação, e, futura hamonizacăo do ramo do direito tributário pois este interfere diretamente no custo da atividade empresarial. Com esta medida pode-se diminuir as desigualdades de concorrència entre os países-membros. Havendo dilerença entre os impostos sobre o consumo, haverá influência direta no preço final

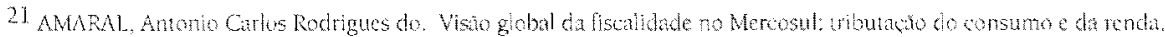

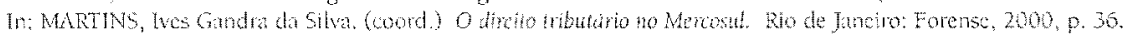

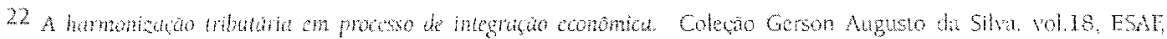

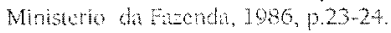

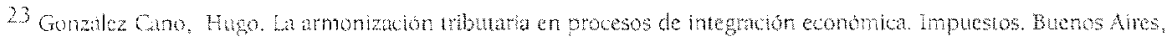
mat 1.991, p. 885

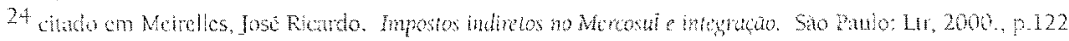


do produto, indo em total desencontro com o objetivo e com os princípios do Mercosul.

Apesar das dificuldades, o Grupo de Trabalho no. 8, estudou o tema 'supressão de barreiras fiscais', durante o mês de maio de 1995, apresentam sugestóes e recomendaçoes aos governos envolvidos na problemática do Mercosul. E recomendou que cada país deverá tender à adoçăo de sistemas de tributaçäo baseados em principio semelhantes para todos os paisesmembros; em tal sentido, entende-se como necessâria a subscrição pelos Estados do Mercosul, de convênio que eliminem a dupla tributação internacional, que é tratada, no presente, por soluçóes parciais; em virtude das dificuldades que existem para adotar um técnica impositiva e eficiente de arrecadação sobre os impostos indiretos, deverá prever-se e instrumentalizarse um período transitório que permita aos Estados-parte adequar-se internamente até alcançar a completa harmonização das distintas legislaçoes tributárias; os Convênios deverão prever a solução por etapas até alcançar a completa harmonização dos sistemas tributários intemos, a fim de evitar os eventuais prejuízos pela perda de arrecadação dos países-membros; para obter êxito na hamonização tributárias que se pretende, os Estados-partes deverão introduzir as modificaçóes necessárias em nível constitucional ou legal, tomando como base os principios da legalidade, da igualdade e da capacidade contributiva.

Para a coordenação e posterior harmonização legislativa tributária e fiscal, um dos pontos importantes desse ajuste é a criação IVA, que é considerado o melhor tributo para fins de coordenação tributaria relativamente a paises integrantes dos agrupamentos econòmicos regionais. Una das grandes vantagens do IVA é que, do ponto de vista do comércio internacional, é um tributo que pode legitimamente ser deduzido das exportaçoes. O IVA pode ser legalmente restituido nas fronteiras, por ajustes tributarios no momento da exportaçäo, se for caso de ajuste das exportações $^{23}$

25 Anaral, Antonio Garlos Rodrigues do, Visão global da liscalidade no Merosul tributapa do consumo e da lenda. In: Martins, ives Gandra da Silva, (coord.) O direto tributario no Merwosul. Fio de Janetro, Forense, 2too, p.42. 
TAIT $^{2 \hbar}$, expōe as justificativas e razōes para adoção do Imposto sobre o Valor Agregado (ou acrescido), sendo as seguintes: a) impostos sobre vendas säo insatisfatónios; b) união aduaneira exige a supressäo de algumas baneiras discriminatórias e o IVA facilita o comércio; c) possibilidade de supressão ou reduçăo de outros impostos com a adoçäo do IVA; d) a evoluçäo dos sisiemas tributátios, muitas vezes, näo se adapta ao desenvolvimento do pais, tornando-se necessária a criação do IVA ${ }^{27}$ e, também a necessidade de coordenação e conseqüente harmonização tributárias para a livre circulação de bens e servicos.

\section{Conclusão}

O VA É considerado o melhor tributo para fins de coordenaçăo tributária relativamente a paises integrantes do agrupamento economicos regionais. Uma das grandes vantagens do IVA é que, do ponto de vista do comércio internacional, é um tributo que pode legitimamente ser deduzido das exportaçoes. Sob o 'General Agreement on Tariffs and Trade (GATT)', um tributo da natureza do IVA pode ser legalmente restituido nas fronteiras, por ajustes tributarios no momento da exportacáa ${ }^{28 .}$.

Em todo o corpo deste ensaio, há o entrave da harmonização legislativa para a efetiva integração no Mercosul. Cada Estado-parte tem sua legislaça interna vigente, sem aplicação imediata. A partir do reconhecimento, por norma constitucional, da primazia dos tratados sobre a lei interna, as avenças internacionais aplicar-se-äo no plano interno tão logo ratificadas, afastando as leis nacionais, no que com ela forem incompativeis. Aos tratados internacionais sera licto conceder isencoes e beneficios fiscais relativamente a tributos estaduais e municipais por força de sua superior posição hierárquica ${ }^{29}$. É necessário a

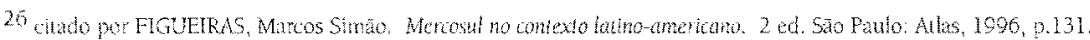

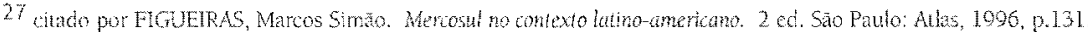

28 AMARAL, Anomo Carlos Rodrigues do. Visão global da fiscalidade no Mercosul: tribuacăo do consumo e da renda. In:

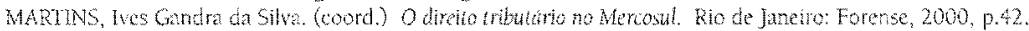

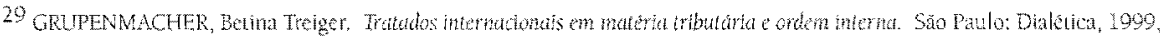
p.lys
} 
hamonização tributária, e, também, o renascer desta idéia pelos Estadospartes.

Para o Mercosul se constituir num mercado comum, passando pela união aduaneira, fase atual, a ênfase ao processo de integração recai mais sobre a livre circulação de bens, sendo importante a estruturação dos impostos sobre o consumo.

Faz-se a afirmação de que os mercados determinam mais a política uributária que os govemos e as sociedades locais face às necessidades de capitais externos, por MARTINS ${ }^{30}$. Com a finalidade de harmonização tributária no Mercosul, os mercados serão ditados pelos capitais externos? $O$ Mercosul, como bloco, com os seus governantes e sua organizacão serão sulicientes para proteger o consumidor? Os capitais externos ditaräo se a integridade do consumidor, bem como os direitos humanos serão ou não respeitados?

Questiona-se, neste final de ensaio, como tornar eficaz a coordenação e a posterior e a consequente harmonização das normas tributárias no Mercosul, e, quanto ao âmbito brasileiro; poderia o IVA ser uma evoluça do ICMS ou, o IVA irá substituir o ICMS e incorporar o IPI e o ISS e, caso isto ocorra, como ficaria e como se resolveria a competencia tributária e a repartiça da receita tributária.

\section{BIBLIOGRAFIA}

AFONSO, Josc Robcro Rodrigues; GORINI, Ana Paula; RAMUND, Júlio Cezar. A mibutacão indireta dos servicos a criaxa de un imposto sobre o valor acondicionado. In: MATTOS FLHO, Ary Oswalde. (coord.) Reforma fiscal coletenca de estudos técnicos. Săo Paulo: DBA Dórea Books and Art, 1904 vol 2.

AMARAL, Antonio Carlos Rodrigues do. Visăo global da fiscalidade no Mercosul: tributacão do consumo c da rendat. In: MARTINS, Ives Gandra da Silva. (coord.) O dircito tributărio no Mcrosul. Rio de Janciro: Forcuse, 2000.

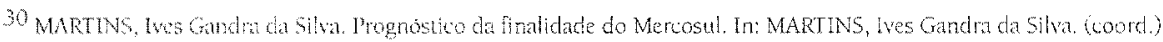

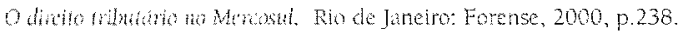


CANO, Hugo González. A hamonizaça tributatia em processo de integracão econômica. Coleça Gerson Augusto da Silva. vol.18, ESAF, Minstério da Fazenda, 1986, p. 23-24.

CANO, Hugo González. La armonización tributaria en procesos de integración conómica. Impuestos. Buenos Aires, may, 1.991.

COST Gustavo de Freitas Cavalcenti. Federdismo 6 ICMS refexos inbuarios. Curitba: Juná, 2000.

DERZ1, Mizabel Abreu Machado. A necessidade da instivicăo do IVA no sistena constiucional tributário braileiro, In: BALTHAZAR, Ubaldo Cesar (org) Refoma tributaria S Merosul. Belo Honzonte. Del Rey, 1999.

DIRTUTO, Carlos Aberto Menezes; MELLO, Celso D. de Abuquerque; MESTIERI, Joăo. Estuto das transfommocs da ordem politica. Rio de laneiro: Renes, 1971.

FERRERA, Pinto. Principios gerais do direto constitucional moderno. 4 ed. São Paulo: Saraiva, 1962 vol.2 FlgueIRAs, Marcos Simão. Merosui no contexto latino americano. 2 ed. Săo Paulo: Atlas, 1996.

FORTE, Unberto. União Europeia comunidade economica européta: direito das comunidades curopeias a harmonizacäo fiscal. Sāo Paulo: Malheiros, 1994.

GRUPFNMACHER, Betina Treiger. Tratados intemacionais em materia tributaria e orden interna. Säo Patilo: Dialética, 1999.

LANGEMANN, Eugenio, Há necessidade de um imposto unico sobre o consumo no ambito do Metcosul? Scquncia. Florianópolis: Untversidade Federal de Santa Catarina, 1995 , wol 16.

LOPES FLHO, Ozires. A necessidade (ou râo) de inclusâo dos serviços no campo de incidencra do IVA.

Sqqûncia. Flomanópols: Universidade Federal de Sana Catarina, 1995, vol 16.

MERELLES, Jose Ricardo. Imposios indiretos no Mcrosul integraca. Săo Paulo: Lr, 2000.

NAKAYAMA, Juiana Kyosen e RIBERO, Maria de Eatima, O imposto sobre o valor agregado (WA) no

Merostl cos diritos fundomentus. Artigo apresentado no Anais das XX Jornadas do 11 ADT, Salvador:

Associano Brasleira de Direito Financeiro, 2000. p.685-713.

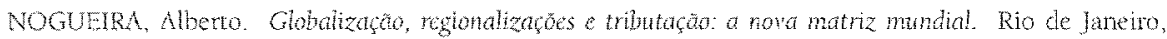
Renovar: 2000.

RES, Eicio Fonseca. Federatismo fiscal. Belo Horizonte: Mandamentos, 2000.

REZENDE, Fenando. A moderna tributacăo do consumo. In: MATTOS FILHO, Ary Oswaldo (coord.)

Refonia fiscal: colctânea de estudos técnicos. Säo Paulo: DBA Dórea Books and Art, 1994. vol 2.

RIBEIRO, Maria de Fátima. Um cnfoque sobre o Mercosul com enfase ao sistema tributário brasilciro. Artigo apresentado no Anais das XX Jornadas do ILADF, Salvador; Associaçăo Brasileira de Direito Financeiro, 2000.

SANTIAGO, Igor Mauler. A harmonizaça das legislacoes tributarias no Mercosu. Consulado na INTERNET, em 17 de janeiro de 2000. http//wwwneofitocom br.

SEREC. Fenando Eduardo; RM, Sin Jae. Hamonizaçăo tributána no Mercosul. In CASELA, Paulo Borba (coord). Contratos intemacionais $e$ direito cconomico no Mercosul apos o temino do perndo do tronsicho. Să Paulo: ITr, 1996

URREST, Esteban Juan e CARDOZO, Horacio Felix. Comentarios sobre la instauración del impuesto al valor aggegado on un estado federal. In: BALTHAZAR, Ubaldo César (org.) Refomá tributária ê Merosul. Belo Horizonte: Del Rey, 1909.

VENTURA, Deisy de Freitas Lima. A ordem juridica do Merosul. Porto Alegre: Livraria do Advogado, 1996. 